\title{
Digestive symptoms in older adults: Prevalence and associations with institutionalization and mortality
}

\author{
Turki AlAmeel MBBS, FRCPC ${ }^{1}$, Mohammed Basheikh MBBS FRCPC ${ }^{2}$, Melissa K Andrew MD PhD FRCPC
}

\author{
T AlAmeel, M Basheikh, MK Andrew. Digestive symptoms in \\ older adults: Prevalence and associations with institutionalization \\ and mortality. Can J Gastroenterol 2012;26(12):881-884.
}

BACKGROUND: Digestive symptoms are common in adults. However, little is known about their prevalence in older adults and the association of digestive symptoms with institutionalization and mortality in community-dwelling older adults.

OBJECTIVE: To determine the prevalence of digestive symptoms among older adults in Canada and whether they are associated with increased risk of institutionalization and mortality, independent of the effect of potential confounders.

METHODS: The present study was a secondary analysis of data collected from community-dwelling participants 65 years of age and older in the Canadian Study of Health and Aging. Measures incuded age, sex, presence of digestive symptoms, cognition, impairment in activities of daily living (ADL) and self-reported health. Outcome measures included death or institutionalization over the 10 years of follow-up. RESULTS: Digestive symptoms were found in 2288 (25.6\%) of the difference in age of six months $(\mathrm{P}=0.007)$. Digestive symptoms were more common among women (28.4\%) than men (20.3\%), among number of impairments in their ADLs $(\mathrm{P}<0.001)$. The presence of digestive symptoms was associated with higher mortality (HR 1.15 [95\% CI 1.05 to 1.25 ] adjusted for age, sex, cognitive function and ADL impairment); however, this association was not statistically significant after adjusting for self-reported health.

CONCLUSION: Although digestive symptoms were associated with increased mortality independent of age and sex, cognition and function, this association was largely explained by poor self-assessed health. Digestive symptoms were not associated with institutionalization

Key Words: Activities of daily living; Aged; Digestive symptoms; Epidemiology; Institutionalization; Mortality 8949 subjects. Those with digestive symptoms were older, with a mean individuals with poor self-reported health and those with an increased

\author{
Les symptômes digestifs chez les adultes plus âgés : \\ la prévalence et les associations avec \\ l'institutionnalisation et la mortalité
}

HISTORIQUE : Les symptômes digestifs sont courants chez les adultes. Cependant, on ne sait pas grand-chose sur leur prévalence chez les adultes âgés et sur l'association des symptômes digestifs à l'institutionnalisation et à la mortalité chez les adultes âgés résidant dans la collectivité.

OBJECTIF : Déterminer la prévalence de symptômes digestifs chez les adultes âgés au Canada et si ces symptômes s'associent à un risque plus élevé d'institutionnalisation et de mortalité, quel que soit l'effet des variables confusionnelles potentielles.

MÉTHODOLOGIE : La présente étude était une analyse secondaire des données colligées auprès de participants de 65 ans et plus résidant dans la collectivité ayant participé à l'Étude sur la santé et le vieillissement au Canada. Les mesures incluaient l'âge, le sexe, la présence de symptômes digestifs, la cognition, la dégradation des activités de la vie quotidienne (AVQ) et l'autoévaluation de la santé. Les mesures d'issue incluaient le décès ou l'institutionnalisation pendant la période de suivi de dix ans.

RÉSULTATS : Les chercheurs ont relevé des symptômes digestifs chez 2288 (25,6 \%) des 8949 sujets. Ceux qui avaient des symptômes digestifs étaient plus âgés, présentant une différence d'âge moyenne de six mois $(\mathrm{P}=0,007)$. Les symptômes digestifs étaient plus courants chez les femmes $(28,4 \%)$ que chez les hommes $(20,3 \%)$, chez les personnes ayant un mauvais état de santé autodéclaré et chez celles présentant une dégradation de plusieurs aspects des AVQ $(\mathrm{P}<0,001)$. La présence de symptômes digestifs s'associait à une mortalité plus élevée (rapport de risque instantané de 1,15 [95 \% IC 1,05 à 1,25] rajusté selon l'âge, le sexe, la fonction cognitive et la dégradation des AVQ). Cependant, cette association n'était pas statistiquement significative après rajustement de l'autoévaluation de l'état de santé.

CONCLUSION : Même si les symptômes digestifs s'associaient à une augmentation de la mortalité quel que soit l'âge, le sexe, la cognition et la fonction, cette association s'expliquait largement par une mauvaise autoévaluation de l'état de santé. Les symptômes digestifs ne s'associaient pas à l'institutionnalisation.

We conducted the present study to determine the prevalence of digestive symptoms and their association with institutionalization and mortality in community-dwelling older adults.

adults $(1,2)$. Most symptomatic individuals do not seek medical attention (2-6). Despite this, digestive symptoms constitute a significant burden on the health care system. In 2004, a primary diagnosis of a digestive disease led to 72 million outpatient visits in the United States; the majority of those patients were $>65$ years of age ( 7 ).

There is a paucity of data regarding the prevalence of digestive symptoms in older Canadians, although studies performed in other countries have revealed that this is a common problem, the impact of which is difficult to gauge (8-10). However, some of these were referral-based studies and their findings may not be applicable to the general population. It also unclear whether older persons who report symptoms are more likely to experience worse outcomes, such as death or institutionalization, compared with asymptomatic subjects.

\section{METHODS}

The present study was a secondary analysis of the Canadian Study of Health and Aging (CSHA), a national, population-based, longitudinal, multicentre cohort study whose original objectives were to determine and investigate the prevalence, incidence and risk factors for dementia and the earlier stages of cognitive impairment. Supplementary objectives covered broader aspects of health and disability among elderly Canadians (11).

The CSHA began in 1991 (CSHA-1), when representative samples of Canadians $\geq 65$ years of age were randomly drawn in 39 urban

${ }^{1}$ Division of Gastroenterology, University of Alberta, Edmonton, Alberta; ${ }^{2}$ Department of Medicine, King Abdulaziz University, Jeddah, Saudi Arabia;

${ }^{3}$ Division of Geriatric Medicine, Dalhousie University, Halifax, Nova Scotia

Correspondence: Dr Turki AlAmeel, Division of Gastroenterology, University of Alberta 2-39 Zeidler Ledcor Centre, 130 University Campus Northwest,

Edmonton, Alberta T6G 2X8. Telephone 780-492-8243, fax 780-492-1455, e-mail talameel@gmail.com

Received for publication March 29, 2012. Acccepted June 5, 2012 
and surrounding rural areas in the 10 Canadian provinces. Subjects were $\geq 65$ years of age at the time of the first survey. Sampling was stratified according to age group, with over-sampling of those 75 to 84 years of age (two times) and $\geq 85$ years of age ( 2.5 times). Those with life-threatening illnesses (eg, on life support measures or with terminal cancer) were excluded. Individuals who declined to participate or who could not be contacted were replaced by others of the same sex, age group and region.

To make population estimates, sample weights were derived to correct for the different populations in each sampling area and for the oversampling of the older groups (12).

The full CSHA study involved 9008 individuals from the community and 1255 from long-term care institutions. The same individuals were contacted again in 1996 (CSHA-2) and 2001 (CSHA-3). The community sampling frame was based on the Canadian provincial universal health insurance plans, with the exception of Ontario, where technical limitations with the health insurance plan list prevented its use at the time. Here, the Enumeration Composite Record was used, which was a composite list of all citizens in Ontario based on electoral lists, updated between elections from information such as property sales. The response rate in the community was $72.1 \%$. The present study included the 8949 community dwellers who were administered the relevant section of the screening questionnaire.

The CSHA screening interview included questions regarding demographics, general health and psychometric tests for cognitive impairment. The interviewers were instructed to collect collateral information from family members or proxy respondents when recording the data, particularly in cases of cognitively impaired respondents in whom personal accounts may have been unreliable.

The question used to determine the presence of digestive symptoms was: "In the past year have you had troubles with your stomach or digestive system? You can just answer Yes or No." Cognitive function was based on the score from the Modified Mini-Mental Status (3MS) examination (13). The $3 \mathrm{MS}$ is a validated cognitive screening instrument with a possible score of 0 to 100 that tests orientation, immediate and remote memory, attention and concentration, language and naming, verbal fluency and executive function. The respondents were categorized as cognitively normal ( $3 \mathrm{MS}$ score $\geq 78$ ) or impaired (3MS score $<78$ ).

Self-rated health was assessed using a 5-point scale ranging from very good to poor; this was taken from the Older American Resources Utilization Study (14).

For these analyses, self-rated health was dichotomized as either good (combining 'very good' or 'good' responses) or poor (in which 'fair', 'poor' and 'very poor' responses were combined). Self-rated health status was missing for 18 individuals $(0.002 \%)$.

Functional status was based on self-report and was assessed using the activities of daily living (ADL) scale from the Older American Resources Utilization Study (14). For our analyses, each of five functional items (eating, dressing, grooming, bathing and toileting) was scored either as 1 (can perform without help) or 0 (needs assistance or unable to perform.)

Participants were categorized according to the number of impairments they reported: no impairments in ADL, one impairment, and two or more impairments in ADL. Nineteen individuals were missing data for one of the five ADL; these individuals were included in the analysis according to the sum of their nonmissing impairments.

Marital status was classified as either married (subjects who were currently married or living in common-law relationships) or unmarried (widowed, divorced, separated and previously married). Marital status data were missing for two individuals.

The CSHA was approved by local ethics committees at all participating study sites.

\section{Outcome measures}

For participants who died during the 10-year follow-up, survival time was calculated as the time between the baseline interview at CSHA-1 and the date of death. Ten-year mortality was coded as either 1 (deceased by the end of CSHA-3) or 0 (alive by the end of CSHA-3). Similarly, institutionalization was coded as 1 (institutionalized by the end of CSHA-3) or 0 (remained in the community). In Canada, it is very rare for institutionalized elderly people to return to the community.

\section{Statistical methods}

All subjects for whom complete data were available were included in the analysis. In all analyses, proportional weights were used to account for sampling methodology (15).

The baseline characteristics of the subjects with digestive symptoms and the asymptomatic group were compared using the $\chi^{2}$ test for proportions and Student's $t$ test for continuous variables. In all analyses, having digestive symptoms was specified as the independent variable, with mortality or institutionalization as dependent variables. The potential confounders (age, sex, self-rated health, ADL dependence and cognitive impairment) were included as covariates in the regression models.

\section{Survival analyses}

Cox proportional hazard regression was used to investigate whether having digestive symptoms was associated with survival, adjusting for potential confounding factors including age, sex, $3 \mathrm{MS}$ score, self-rated health and number of impairments in ADL. The results of the Cox regression were reported as HRs with 95\% CIs.

\section{Institutionalization analyses}

Multivariable logistic regression models were used to control for potential confounding variables and to determine the independent association between digestive symptoms and incident institutionalization.

All analyses were performed using STATA version 8.1 (Stata Corp, USA) and were weighted to account for the sampling methodology.

\section{RESULTS}

Data regarding digestive symptoms of 25 subjects were missing and were necessarily excluded from the analysis. Because of their small number, their exclusion is unlikely to have significantly affected the results.

Of the 8949 participants included, 2288 (25.6\%) reported having difficulty with their stomach or digestive system in the past year. More women (28.4\%) complained of digestive symptoms than men $(20.3 \%$; $\mathrm{P}<0.001)$. Participants $>75$ years of age were more likely to report symptoms $(\mathrm{P}=0.04)$ and the mean age of subjects with digestive symptoms was six months older than those without symptoms $(\mathrm{P}=0.007)$.

The percentage of subjects complaining of digestive symptoms was similar between those who were single $(25.9 \%)$ at the time of the survey and those who were married $(24.2 \%)$.

Digestive symptoms were found more frequently among subjects with cognitive impairment as defined by a $3 \mathrm{MS}$ score $<78$, those with poor self-reported health and patients with an increased number of impairments in ADLs (all $\mathrm{P}<0.001\left[\chi^{2}\right.$ test]) (Table 1$)$.

The presence of digestive symptoms was associated with higher mortality (unadjusted HR 1.19 [95 \% CI 1.06 to 1.34]). The relationship between mortality and digestive symptoms remained statistically significant after adjusting for age, sex, cognitive function and ADL impairment (HR 1.15 [95\% CI 1.05 to 1.25$]$ ). However, after adjusting for self-reported health, mortality was similar between those with and without digestive symptoms (HR 1.05 [95\% CI 0.96 to 1.15$]$ ) (Table 2).

There was no association between digestive symptoms and institutionalization.

\section{DISCUSSION}

The present study was one of the first to report on the prevalence of gastrointestinal symptoms in community-dwelling elderly Canadians. More than $25 \%$ of Canadians $\geq 65$ years of age complained of digestive symptoms. At the time of CSHA data collection, this corresponded to more than 740,000 affected individuals in Canada. Digestive symptoms were more prevalent among subjects with advanced age and functional or cognitive impairments. 
TABLE 1

Baseline characteristics of individuals with and without digestive symptoms (weighted $n=8917$ )

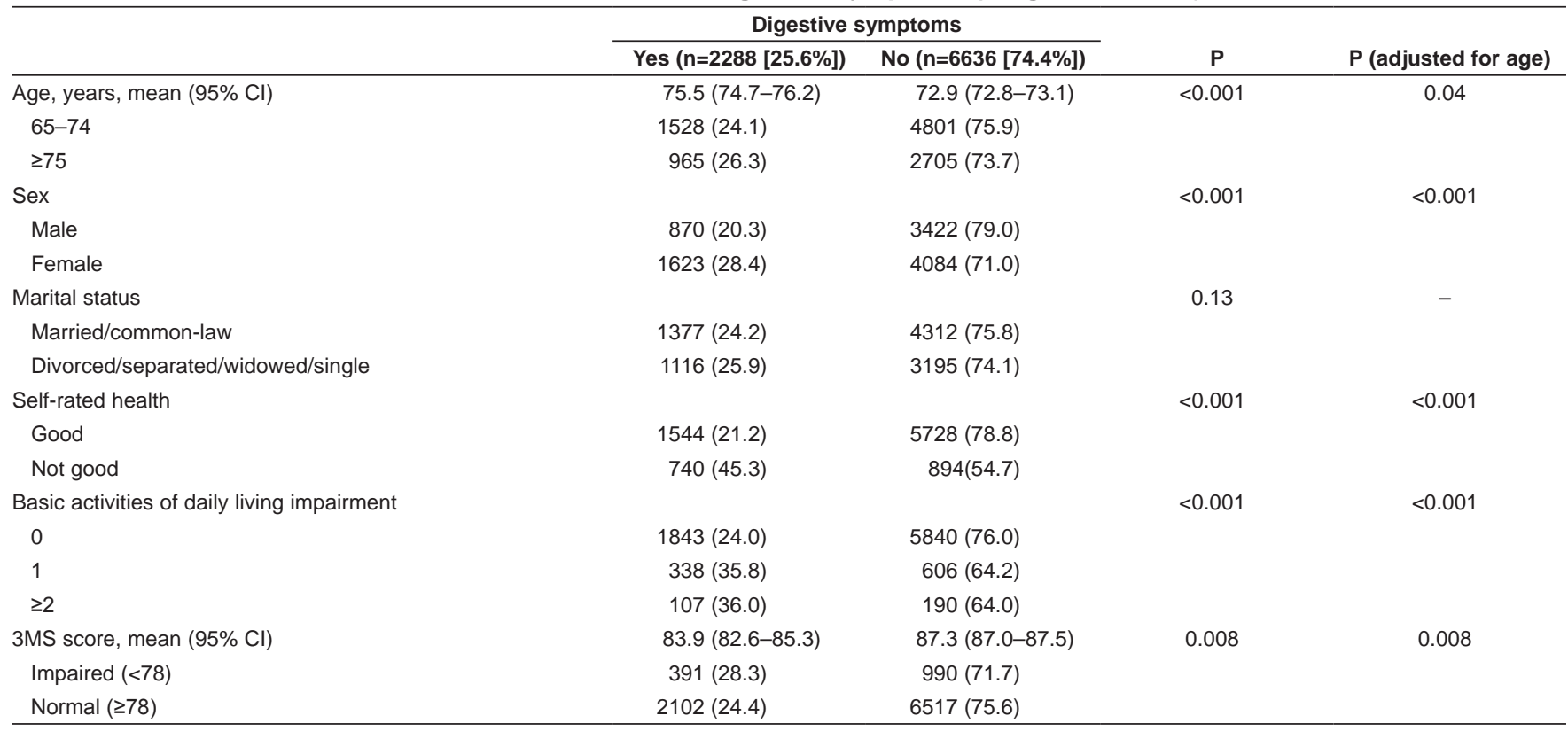

Data presented as $n$ (\% [percentages calculated by row]) unless otherwise indicated. 3MS Modified Mini-Mental Status questionnaire

TABLE 2

Outcomes (mortality and institutionalization) in individuals with digestive symptoms compared with those without

\begin{tabular}{|c|c|c|c|c|c|}
\hline & \multicolumn{5}{|c|}{ Digestive symptoms model } \\
\hline & $\begin{array}{c}1 \\
\text { (Unadjusted) }\end{array}$ & $\begin{array}{c}2 \\
\text { (Adjusted for age, sex) }\end{array}$ & $\begin{array}{c}3 \\
\text { (Adjusted for age, } \\
\text { sex and cognition }\end{array}$ & $\begin{array}{c}4 \\
\text { (Adjusted for age, sex, } \\
\text { cognition and ADLs }\end{array}$ & $\begin{array}{c}5 \\
\text { (Adjusted for age, } \\
\text { sex, cognition, ADLs } \\
\text { and SRH }\end{array}$ \\
\hline \multicolumn{6}{|l|}{ Mortality risk } \\
\hline OR (95\% Cl); P & 1.19 (1.06-1.34); 0.004 & 1.27 (1.11-1.46); <0.001 & 1.26 (1.10-1.45); 0.001 & 1.20 (1.04-1.37); 0.11 & $1.06(0.92-1.22) ; 0.42$ \\
\hline HR (95\% Cl); P & $1.14(1.04-1.25) ; 0.005$ & 1.19 (1.09-1.29); <0.001 & 1.18 (1.09-1.29); <0.001 & 1.15 (1.05-1.25); 0.002 & 1.05 (0.96-1.15); 0.31 \\
\hline $\begin{array}{l}\text { Odds of institutionalization } \\
\text { OR }(95 \% \mathrm{Cl}) ; \mathrm{P}\end{array}$ & 1.08 (0.89-1.31); 0.45 & 1.05 (0.86-1.29); 0.64 & 1.04 (0.85-1.28); 0.71 & 0.96 (0.78-1.19); 0.71 & $0.88(0.71-1.10) ; 0.26$ \\
\hline
\end{tabular}

Digestive symptoms (Yes/No), age (years),sex, number of basic activity of daily living (ADL) impairments, and self-rated health (SRH, good versus not good). Mortality was modelled using Cox regression. Results are presented as HRs, and OR with logistic regression. ORs for institutionalization were derived from logistic regression models

The prevalence of gastrointestinal symptoms in our study (25\%) was similar to what has been reported in previously published studies. In a general population study conducted in Canada (1), the prevalence of upper gastrointestinal symptoms was $28.6 \%$. Abdominal pain in the preceding year was reported by $25.2 \%$ of subjects in a British elderly population (9) and $24.3 \%$ of seniors living in Olmsted County, Minnesota (USA) (10). Upper dyspeptic symptoms, defined as epigastric pain, heart burn or acid reflux, was found in $25.7 \%$ of men and $32.5 \%$ of women in a Danish elderly population (8).

In the present study, women reported more digestive symptoms than men, a finding shared by other epidemiological studies involving elderly populations $(8)$ and adults in general $(10,16)$. In a previous Canadian study, patients were surveyed and their symptoms were classified based on Rome II classification: more women reported functional abdominal pain, bowel and anorectal disorders, while functional esophageal and gastroduodenal disorders were more prevalent in men (17). Several lines of inquiry have attempted to explain this sexrelated difference in functional gastrointestinal disorders on the basis of behavioural, hormonal, psychological or motility factors. However, the exact reason for the difference remains elusive $(18,19)$.

In population-based studies of seniors, few have examined the differences in the prevalence of digestive symptoms among different age groups. Our results showed that subjects $>75$ years of age were more likely to report having digestive symptoms. Others have reported different results. Data from the United States revealed that the prevalence of dyspepsia in the elderly was similar among age groups (20). This variability may have been due to the difference in the question asked or due to the smaller number of subjects in that study $(n=1375)$, which made it more difficult to detect difference in prevalence according to age.

To our knowledge, the present study was the first to examine the association between digestive symptoms and other important aspects of assessing older adults such as cognitive function and ability to perform ADLs. Impairment in cognitive function was associated with a greater prevalence of digestive symptoms, as were poor self-reported health and impairments in ADLs.

In the present study, we found that the presence of digestive symptoms was associated with higher mortality even after adjusting for age, sex, and cognitive function and ADL impairment. Nevertheless, the increased mortality was statistically insignificant after adjusting for self-reported health. This suggests that the presence of digestive symptoms may be a marker of deterioration in health, cognitive and/or functional status rather than a risk factor for mortality in itself. Another possibility is that digestive symptoms contribute importantly 
to people's self-perception of their health status. Marital status at the time of the survey had no effect on the prevalence of digestive symptoms and digestive symptoms did not predict institutionalization.

The major strength of the present study is that the data were derived from a population-based survey generating a large representative sample of community-dwelling elderly people with 10 -year follow-up of individual subjects and robust measures of cognition and function. One of the advantages of an epidemiological approach to digestive symptoms is the ability to study patients with variable symptom severity including those who had not sought medical advice (21). Other studies have shown that, in elderly populations, only $18 \%$ to $23 \%$ had sought health care for their gastrointestinal complaints in the previous year (10). The decision to consult health care providers is probably affected by the frequency and severity of symptoms (9).

Nevertheless, our study has limitations. Our survey was based on self-reported data, which can be affected by recall bias and may underestimate the prevalence of digestive symptoms (22). Another concern is misreporting if the subject was very cognitively impaired, although collateral information from proxy respondents was taken into account as much as possible in such cases. The state of health was also selfreported and its reflection of the patient's true health status is subject to personal subjective judgement. Accordingly, self-assessed health has been shown to correlate well with objective measures of health and mortality, and is a commonly used and well-validated measure (23). We relied on the subject's own assessment of severity by asking about "troubles with digestive system or stomach". Other epidemiological studies have used a similar approach (21). There is considerable variability in the type of question subjects were asked to investigate dyspepsia among different epidemiological studies. Among the most commonly used criteria in the functional gastrointestinal disorders literature are the Rome criteria (24). At the time of our baseline survey in 1991, the Rome criteria were not widely used. The elderly bowel symptom questionnaire (25) is another validated score that was published after our survey was conducted. The definition chosen for the present study, based on a broad self-report question, was designed to be as inclusive as possible of any symptoms suggestive of dyspepsia.

\section{CONCLUSION}

The present large epidemiological study showed that digestive symptoms affected more than $25 \%$ of elderly Canadians. Digestive symptoms were associated with higher mortality; however, this association was largely explained by poor self-assessed health.

ACKNOWLEDGEMENTS: The data reported in this article were collected as part of the Canadian Study of Health and Ageing. The core study was funded by the Seniors' Independence Research Program, through the National Health Research and Development Program (project no 66063954-MC[S]) The CSHA data are held in-house at the Geriatric Medicine Research Unit, Dalhousie University. The sponsor had no role in these analyses. Melissa Andrew was supported by a clinical research initiative fellowship from the Canadian Institutes for Health Research and by a Killam Scholarship.

AUTHOR CONTRIBUTIONS: TA: Designed the study, reviewed the literature and prepared the manuscript except for the results section. MB: Reviewed the literature and edited the manuscript. MA: Performed the statistical analysis, wrote the results section and edited the manuscript.

DISCLOSURES: The authors have no financial disclosures or conflicts of interest to declare.

\section{REFERENCES}

1. Tougas G, Chen Y, Hwang P, et al. Prevalence and impact of upper gastrointestinal symptoms in the Canadian population: Findings from the DIGEST study. Domestic/International Gastroenterology Surveillance Study. Am J Gastroenterol 1999;94:2845-54.

2. Drossman DA, Li Z, Andruzzi E, et al. U.S. householder survey of functional gastrointestinal disorders. Prevalence, sociodemography, and health impact. Dig Dis Sci 1993;38:1569-80.

3. Penston JG, Pounder RE. A survey of dyspepsia in Great Britain. Aliment Pharmacol Ther 1996;10:83-9.

4. Agréus L. Socio-economic factors, health care consumption and rating of abdominal symptom severity. A report from the abdominal symptom study. Fam Pract 1993;10:152-63.

5. Talley NJ, Weaver AL, Zinsmeister AR. Impact of functional dyspepsia on quality of life. Dig Dis Sci 1995;40:584-9.

6. Holtmann G, Goebell H, Talley NJ. Dyspepsia in consulters and non-consulters: Prevalence, health-care seeking behaviour and risk factors. Eur J Gastroenterol Hepatol 1994;6:917-24.

7. Everhart JE, Ruhl CE. Burden of digestive diseases in the United States part I: Overall and upper gastrointestinal diseases. Gastroenterology 2009;136:376-86.

8. Kay L. Prevalence, incidence and prognosis of gastrointestinal symptoms in a random sample of an elderly population. Age Ageing 1994;23:146-9.

9. Chaplin A, Curless R, Thomson R, et al. Prevalence of lower gastrointestinal symptoms and associated consultation behaviour in a British elderly population determined by face-to-face interview. Br J Gen Pract 2000;50:798-802.

10. Talley NJ, O'Keeffe EA, Zinsmeister AR, et al. Prevalence of gastrointestinal symptoms in the elderly: A population-based study. Gastroenterology 1992;102:895-901.

11. Canadian Study of Health and Aging: Study methods and prevalence of dementia. CMAJ 1994;150:899-913.

12. McDowell I, Aylesworth R, Stewart M, et al. Study sampling in the Canadian Study of Health and Aging. Int Psychogeriatr 2001;13(Supp 1):19-28.

13. Teng EL, Chui HC. The Modified Mini-Mental State (3MS) examination. J Clin Psychiatry 1987;48:314-8.

14. Fillenbaum GG. Multidimensional functional assessment of older adults: The Duke Older Americans Resources And Services Procedures. Hillsdale: Lawrence Erlbaum, 1988.

15. Rockwood K, Wolfson C, McDowell I. The Canadian Study of Health and Aging: Organizational lessons from a national, multicenter, epidemiologic study. Int Psychogeriatr 2001;(13 Supp 1):233-7.

16. Shaib Y, El-Serag HB. The prevalence and risk factors of functional dyspepsia in a multiethnic population in the United States. Am J Gastroenterol 2004;99:2210-6.

17. Thompson WG, Irvine EJ, Pare P, et al. Functional gastrointestinal disorders in Canada: First population-based survey using Rome II criteria with suggestions for improving the questionnaire. Dig Dis Sci 2002;47:225-35.

18. Chang L, Toner BB, Fukudo S, et al. Gender, age, society, culture, and the patient's perspective in the functional gastrointestinal disorders. Gastroenterology 2006;130:1435-46.

19. Chang L, Heitkemper MM. Gender differences in irritable bowel syndrome. Gastroenterology 2002;123:1686-701.

20. Talley NJ, Evans JM, Fleming KC, et al. Nonsteroidal antiinflammatory drugs and dyspepsia in the elderly. Dig Dis Sci 1995;40:1345-50.

21. Agréus L, Svärdsudd K, Nyrén O, et al. Irritable bowel syndrome and dyspepsia in the general population: Overlap and lack of stability over time. Gastroenterology 1995;109:671-80.

22. Manning AP, Wyman JB, Heaton KW. How trustworthy are bowel histories? Comparison of recalled and recorded information. BMJ 1976;2:213-4.

23. Idler EL, Benyamini Y. Self-rated health and mortality: A review of twenty-seven community studies. J Health Soc Behav 1997;38:21-37.

24. Drossman DA, Thompson WG, Talley NJ, et al. Identification of subgroups of functional bowel disorders. Gastroenterol Int 1990;3:159-17.

25. O'Keefe EA, Talley NJ, Tangalos EG, et al. A bowel symptom questionnaire for the elderly. J Gerontol 1992;47:M116-21. 


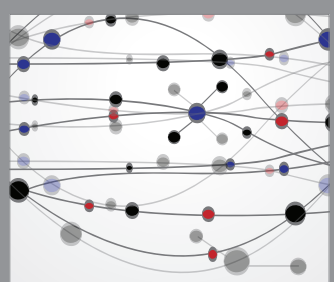

The Scientific World Journal
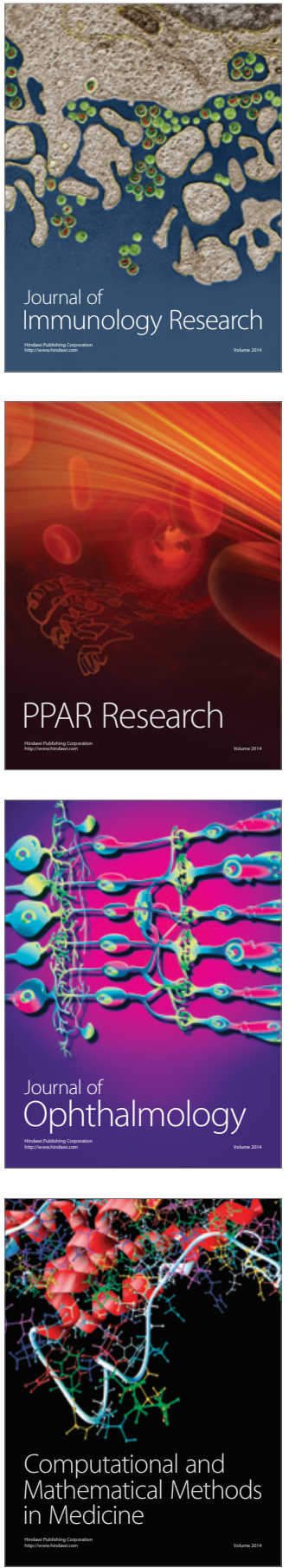

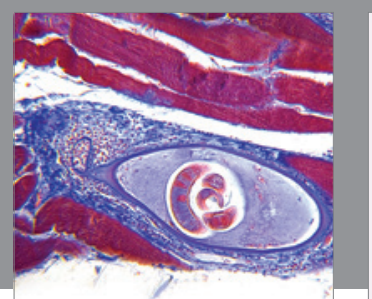

Gastroenterology Research and Practice

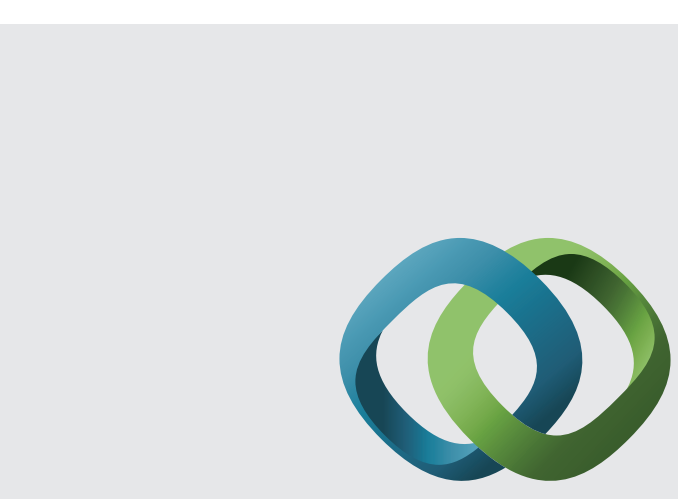

\section{Hindawi}

Submit your manuscripts at

http://www.hindawi.com
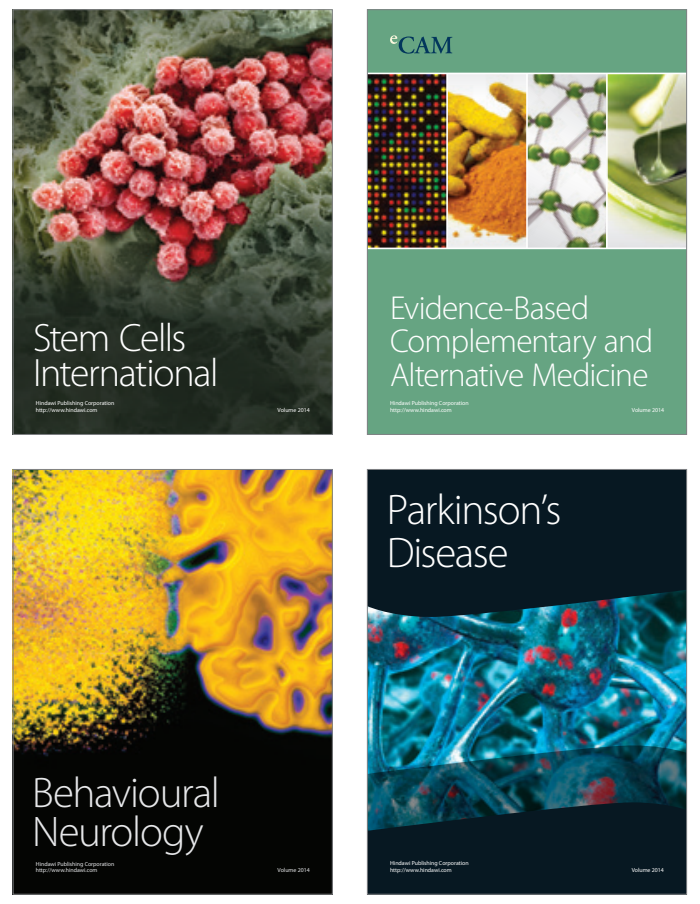
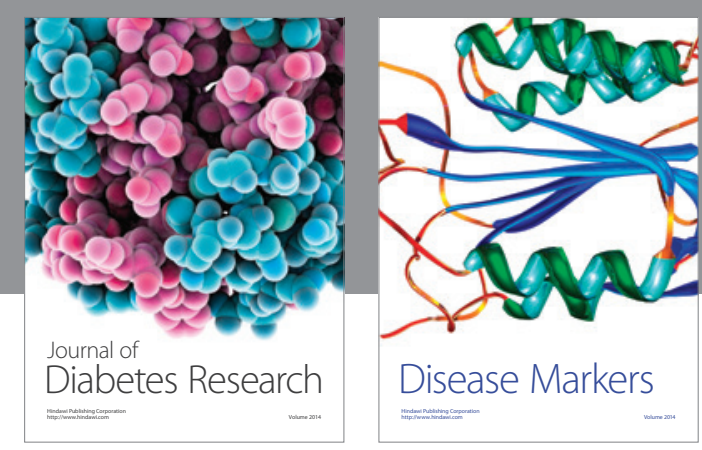

Disease Markers
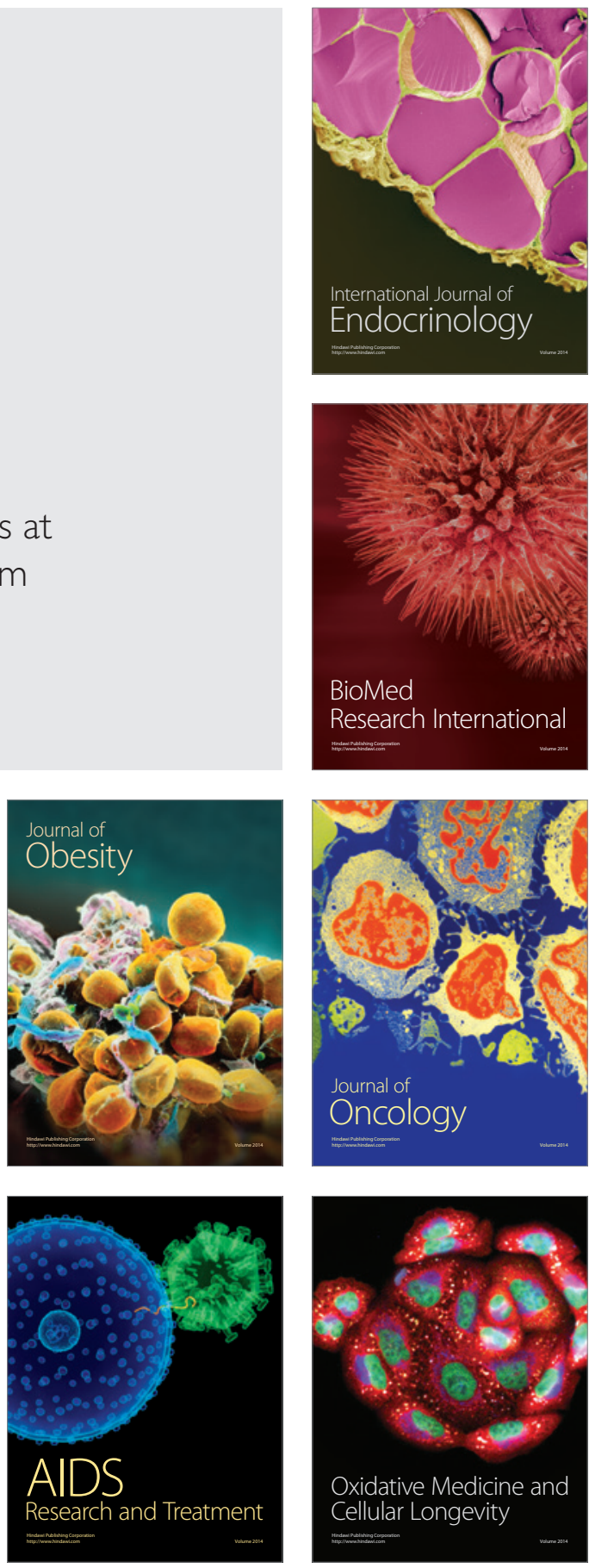